J. Product. \& Dev., 26(2):311-323(2021)

\title{
ACTIVITY STUDY OF FRESH AND FROZEN-THAWED SPERMATOZOA ON INTRACYTOPLASMIC SPERM INJECTION OUTCOME
}

\author{
M.S. Gad ${ }^{1}$; El-Fiky B.A ${ }^{2}$; Ebrahim A. Sabra ${ }^{2}$ and Hanan K. El-Saiedy ${ }^{2}$
}

1. Obs. \& Gyn Department, Faculty of Medicine, Menoufia University, Egypt

2. Animal Biotechnology Department, Genetic Engineering and Biotechnology Research Institute, University of Sadat City, Egypt.

\section{ABSTRACT:}

To assess fertilization, implantation, and pregnancy rates in patients undergoing intracytoplasmic sperm inject (ICSI) using fresh and cryopreserved sperm from ejaculated semen samples. Retrospective study, from a total of 60 patients, 44 ICSI cycles were included in this study. Fertilization, implantation, and pregnancy rates were evaluated; 20 cycles of ICSI (cryopreserved-sperm group) and 20 cycles of ICSI (fresh-sperm group). Also, divided the outcomes according to the semen characteristics, normozoospermia, oligozoospermia, asthenozoospermia, and oligoasthenozoospermia. Overall, normal-fertilization rates were higher using fresh sperm compared with cryopreserved sperm.

Cycles performed in patients with normozoospermia or oligozoospermia had similar fertilization, implantation, and pregnancy rates using fresh or cryopreserved sperm. When asthenozoospermic and oligoasthenozoospermic semen samples were used, the normalfertilization rate was higher with fresh sperm compared with cryopreserved sperm. However, implantation and pregnancy rates were similar in fresh and cryopreserved sperm samples from patients with asthenozoospermia or oligoasthenozoospermia.

In conclusion, semen with abnormalities in the motility may be more susceptible to sperm cryopreservation damage, resulting in lower fertilization rates. However, once the oocyte is fertilized, implantation and pregnancy rates are similar to those in patients with oligozoospermia and normozoospermia.

Key words: Semen, cryopreservation, ICSI, spermatozoa, fertilization 


\section{INTRODUCTION}

Since the introduction of a method for freezing human semen, the indications for sperm cryobanking have been expanded greatly by recent breakthroughs in assisted reproduction, for one's own future use and donor banking (Mortimer, 2004 and Anger et al., 2003). However, it has been shown that the process of freezing and thawing is related to a variable loss of sperm quality (Marcus-Braun et al., 2004). Although the adverse effect of freezing and thawing on sperm quality is even more pronounced in cases of poor semen quality, with the advent of ICSI, only a small number of motile spermatozoa are required for a successful fertilization (Kuczynski et al., 2001; Palermo et al., 1992 and Tournaye, 1999). In fact, ICSI can be performed with fresh and cryopreserved spermatozoa from ejaculated semen from patients with oligoasthenoteratozoospermia, or from spermatozoa extracted from the epididymis or testis, in cases of obstructive or nonobstructive azoospermia (Palermo et al., 1999; Pasqualotto et al., 2002 and Van Steirteghem et al., 1998).

It is well known that intrauterine insemination with cryopreserved sperm results in a lower pregnancy rate compared with fresh sperm, but many studies have shown that fertilization and pregnancy rates for ICSI using cryopreserved spermatozoa are similar to those for ICSI using freshly obtained sperm (Anger et al., 2003; Marcus-Braun et al., 2004 and Kuczynski et al. , 2001 ; Schlegel et al.,1999; Perraguim-Jayot et al.,1997; Gil-Salom et al., 1998; De Croo et al., 1998 and Sailer , et al ., 1995 ). Even though there is no doubt that cryopreserved spermatozoa can be used to fertilize oocytes by ICSI, more studies comparing the efficacy of ICSI with either fresh or cryopreserved ejaculated spermatozoa from infertile patients should be performed. Also, the majority of studies comparing fresh and cryopreserved sperm have shown results from sperm surgically retrieved (Schlegel et al., 1999; Gil-Salom et al ., 1998 and Madgar et al., 1998).

Therefore, the aim of this study was to evaluate fertilization, implantation, and pregnancy rates in patients undergoing ICSI with fresh and cryopreserved ejaculated semen.

\section{MATERIALS AND METHODS}

\section{Subjects}

This retrospective study was performed at Fertility-Assisted Fertilization Center (Nile Center for IVF) from January 2019 to Feb 
2020. From a total of 60 patients, 40 ICSI cycles. The cycles were divided into two groups; 20 cycles were performed with cryopreserved ejaculated sperm (cryopreserved sperm group), and in the same period, 20 cycles were performed with fresh ejaculated semen (fresh sperm group).

Complete history, physical examinations, and hormone evaluations were performed. Patients were informed regarding ICSI technique with fresh or cryopreserved spermatozoa and the possible complications of the procedures.

To evaluate the contribution of sperm condition on fertilization, implantation, and pregnancy rates, the oocyte factor of infertility was excluded. To exclude the oocyte factor, patients older than 35 years of age and those who had fewer than four follicles retrieved were not included in the study.

In this study compared women's age, sperm concentration and motility; number of oocytes retrieved and embryos transferred; and fertilization, implantation, and pregnancy rates between cycles performed with fresh sperm and cryopreserved sperm. Also, compared the same variables in cycles performed in normozoospermic, oligozoospermic, asthenozoospermic, and oligoasthenozoospermic men using fresh and cryopreserved semen.

In addition, this study evaluated patients according to the sperm characteristics assessed before cryopreservation on the basis of the World Health Organization definition : normozoospermic patients (fresh-sperm group, n 6 vs. cryopreserved sperm group, n 6 ), oligozoospermic patients (fresh-sperm group, n 5 vs. cryopreserved sperm group, n 6 ), asthenozoospermic patients (fresh-sperm group, n 4 vs. cryopreserved sperm group, n 3 ), and oligoasthenozoospermic patients (fresh-sperm group, n 5 vs. cryopreserved sperm group, n 5 ).

\section{Ovarian stimulation and oocyte Retrieval}

The female partners were subjected to a protocol of controlled ovarian stimulation as follows: gonadotropin releasing hormone (GnRHa) agonist (leuprolide acetate) for 14 days. When serum $\mathrm{E}_{2}$ concentrations were $40 \mathrm{pg} / \mathrm{mL}$ and no ovarian cystic structures were observed on ultrasound examinations, ovarian stimulation was started with recombinant FSH in a stepdown protocol, until a minimum of two follicles reached an average diameter of $18 \mathrm{~mm}$. 
Oocyte retrieval was performed 36 hours after the administration of $10,000 \mathrm{IU}$ of hCG under transvaginal ultrasonography. Oocytes were incubated in human tubal fluid medium supplemented with $7.5 \%$ synthetic serum substitute, for 3-5 hours before cumulus cell removal. Cumulus cells were removed from the oocytes by placing them in hyaluronidase at a concentration of $80 \mathrm{IU} / \mathrm{mL}$ for 30-60 seconds. Oocytes were transferred to fresh medium, and the corona cells were removed by gentle pipetting in and out.

\section{Cryopreservation}

Semen was collected by masturbation after 3-5 days of abstinence. The ejaculates were allowed to liquefy at $37^{\circ} \mathrm{C}$ and examined within $0.5 \mathrm{~h}$ of collection. The evaluation according to World Health Organisation (WHO) criteria (World Health Organization, 2010) was carried out under a light microscope. After liquefaction, semen was concentrated by centrifugation ( $800 \mathrm{~g}$ ) and an aliquot from each sample was gently diluted (1:1) with freezing medium (Life Global) as medium for cryopreservation containing $15 \%$ of glycerol. After an equilibration period at $37^{\circ} \mathrm{C}$ for 10 min, the mixture was aspirated into $0.5 \mathrm{ml}$ straws. The straws were frozen according to a slow protocol, at $-20^{\circ} \mathrm{C}$ for 8 minutes, the straws were submerged in liquid nitrogen vapor at $-79^{\circ} \mathrm{C}$ for 2 hours, before immersion in liquid nitrogen at $-196^{\circ} \mathrm{C}$ for long-term storage.

One cryovial from each patient was used for an initial post thaw analysis after storage for 24 hours. The vial was placed at room temperature for 5 minutes and then incubated at $37^{\circ} \mathrm{C}$ for 20 minutes. It further was processed for use by dilution with human tubal fluid-HEPES and then by centrifuge processing to remove the cryoprotectant. A 5-L aliquot of semen then was analyzed for sperm count and motility and was compared with the prefreeze results to calculate the concentration of spermatozoa that survived the cryopreservation process.

\section{Procedure for ICSI}

The ICSI procedure was performed with oocytes in metaphase II. The microinjection dish was prepared by pipetting seven droplets of $4 \mathrm{~L}$ of human tubal fluid medium plus HEPES plus $10 \%$ synthetic serum substitute into the center of the dish. The center droplet was removed and replaced with $4 \mathrm{~L}$ of polyvinylpyrrolidone solution. Prepared sperm were added to the drop of polyvinylpyrrolidone solution, and the oocytes then were placed into the drops of medium. The droplets were overlaid with 
mineral oil. Intracytoplasmic sperm injection was performed on a heated stage microscope. After oocytes had been injected, they were rinsed and placed in equilibrated growing medium (human tubal fluid-synthetic serum substitute, $15 \%$ ).

The micromanipulated oocytes were incubated in 50 - to $100-\mathrm{L}$ drops in a culture dish overlaid with mineral oil and were observed for fertilization 16-18 hours after the ICSI procedure. Abnormally fertilized or unfertilized oocytes were removed from the dish. Twenty-four hours later, cleavage of fertilized oocytes was assessed. Embryo transfer was performed approximately 72 hours after injection. All ICSI procedures were performed by the same person. The embryo score was determined by morphological evaluation from the time we assessed oocyte fertilization to the time to transfer on day 3 .

\section{Statistical analysis}

Geometric means and standard deviation (SD) were calculated from raw data. Because of nonnormal distribution of values, they were submitted to logarithmic transformation before analysis. The groups were compared by Pearson Chi-Square test, Fisher's exact test, Npar test and Mann-Whitney test. $\mathrm{P}$ value less than 0.05 was considered statistically significant.

\section{RESULTS}

The overall results for woman's age; sperm concentration and motility; number of oocytes retrieved; embryos transferred; and normalfertilization, implantation, and pregnancy rates from the initial number of cycles $(n=44)$ are depicted in (Table 1$)$.

The groups studied presented similar embryo scores as well as percentage of morphologically good-quality embryos.

When cycles in which women who were older than 35 years of age and had fewer than four oocytes retrieved were excluded, observed that the normal-fertilization rates were higher with fresh sperm than with cryopreserved sperm (Table 2).

When normozoospermic patients with fresh vs. cryopreserved sperm were compared, pregnancy rates were similar ( $\mathrm{P}>$.05; Table 3). When oligozoospermic patients with fresh vs. cryopreserved sperm were compared, pregnancy $(60.0 \%$ vs.50.0\%) rates were not different $(\mathrm{P}>.05)$. 
Table 1 : Characteristics of the population from initial number of cycles:

\begin{tabular}{|l|c|c|c|c|c|c|c|}
\hline \multicolumn{2}{|l|}{ Group } & $\begin{array}{c}\text { Women's } \\
\text { Age (years) }\end{array}$ & $\begin{array}{c}\text { Sperm } \\
\text { concentration } \\
\text { (Million/ml) }\end{array}$ & $\begin{array}{c}\text { Sperm } \\
\text { motility } \\
(\%)\end{array}$ & $\begin{array}{c}\text { No. } \\
\text { of } \\
\text { oocytes }\end{array}$ & Fertilization & $\begin{array}{c}\text { No. of } \\
\text { Embryos } \\
\text { Transferred }\end{array}$ \\
\hline \multirow{2}{*}{$\begin{array}{l}\text { Normozoosp } \\
\text { ermia }\end{array}$} & $\mathrm{Z}$ & $-.243-$ & $-1.043-$ & $-.165-$ & $-1.687-$ & $-1.851-$ & $-.173-$ \\
\cline { 2 - 8 } & $\mathrm{P}$ value & .808 & .297 & .869 & .092 & .064 & .863 \\
\hline \multirow{2}{*}{$\begin{array}{l}\text { Oligozoosper } \\
\text { mia }\end{array}$} & $\mathrm{Z}$ & $-.277-$ & $-.185-$ & $-1.208-$ & $-1.651-$ & $-1.477-$ & $-1.208-$ \\
\cline { 2 - 8 } & $\mathrm{P}$ value & .782 & .853 & .227 & .099 & .140 & .227 \\
\hline $\begin{array}{l}\text { Athenozoosp } \\
\text { ermia }\end{array}$ & $\mathrm{Z}$ & $-1.061-$ & $-.714-$ & $-.900-$ & $-.367-$ & .000 & .000 \\
\cline { 2 - 8 } & $\mathrm{P}$ value & .289 & .476 & .368 & .714 & 1.000 & 1.000 \\
\hline \multirow{2}{*}{$\begin{array}{l}\text { Oligoathenoz } \\
\text { oospermia }\end{array}$} & $\mathrm{Z}$ & $-.211-$ & $-2.514-$ & $-2.447-$ & $-.105-$ & $-.316-$ & $-.346-$ \\
\cline { 2 - 8 } & $\mathrm{P}$ value & .833 & .012 & .014 & .916 & .752 & .729 \\
\hline
\end{tabular}

Note: $\mathrm{P}<.05$ was considered significant.

Table 2: Characteristics of cycles from patients with oocyte factors excluded

\begin{tabular}{|c|c|c|c|c|c|c|c|}
\hline \multicolumn{3}{|l|}{ Semen } & \multirow{2}{*}{$\begin{array}{c}\text { Sperm } \\
\text { concentration } \\
\text { (Million/ml) }\end{array}$} & \multirow{2}{*}{$\begin{array}{c}\begin{array}{c}\text { Sperm } \\
\text { motility } \\
(\%)\end{array} \\
20 \\
\end{array}$} & \multirow{2}{*}{$\begin{array}{c}\begin{array}{c}\text { No. } \\
\text { of } \\
\text { oocytes }\end{array} \\
20 \\
\end{array}$} & \multirow{2}{*}{\begin{tabular}{|c|} 
Fertilization \\
\\
20 \\
\end{tabular}} & \multirow{2}{*}{$\begin{array}{c}\begin{array}{c}\text { No. of } \\
\text { Embryos } \\
\text { Transferred }\end{array} \\
20 \\
\end{array}$} \\
\hline \multirow{9}{*}{ Fresh } & \multirow{2}{*}{$\mathrm{N}$} & Valid & & & & & \\
\hline & & Missing & 0 & 0 & 0 & 0 & 0 \\
\hline & \multicolumn{2}{|l|}{ Mean } & 27.25 & 35.93 & 7.15 & 3.85 & 2.75 \\
\hline & \multicolumn{2}{|c|}{ Std. Deviation } & 30.601 & 26.476 & 4.344 & 2.059 & .967 \\
\hline & \multicolumn{2}{|l|}{ Minimum } & 0 & 1 & 3 & 2 & 2 \\
\hline & \multicolumn{2}{|l|}{ Maximum } & 100 & 75 & 20 & 8 & 6 \\
\hline & \multirow{3}{*}{ Percentiles } & 1st quartile & .88 & 5.00 & 4.00 & 2.00 & 2.00 \\
\hline & & median & 14.00 & 50.00 & 6.50 & 3.00 & 3.00 \\
\hline & & 3rd quartile & 47.50 & 57.50 & 8.00 & 5.75 & 3.00 \\
\hline \multirow{9}{*}{ Cryo } & \multirow{2}{*}{$\mathrm{N}$} & Valid & 20 & 20 & 20 & 20 & 20 \\
\hline & & Missing & 0 & 0 & 0 & 0 & 0 \\
\hline & \multicolumn{2}{|l|}{ Mean } & 34.74 & 41.50 & 12.10 & 9.05 & 2.65 \\
\hline & \multicolumn{2}{|c|}{ Std. Deviation } & 45.468 & 19.941 & 9.984 & 8.056 & .875 \\
\hline & \multicolumn{2}{|l|}{ Minimum } & 0 & 5 & 1 & 1 & 1 \\
\hline & \multicolumn{2}{|l|}{ Maximum } & 160 & 70 & 43 & 33 & 4 \\
\hline & \multirow{3}{*}{ Percentiles } & 1st quartile & 2.75 & 26.25 & 6.25 & 3.50 & 2.00 \\
\hline & & median & 8.50 & 40.00 & 10.00 & 6.50 & 3.00 \\
\hline & & 3rd quartile & 63.00 & 60.00 & 18.00 & 13.00 & 3.00 \\
\hline
\end{tabular}

Note: $\mathrm{P}<.05$ was considered significant 


\section{Continuous of Table 2}

\begin{tabular}{|l|c|c|c|c|c|}
\hline & $\begin{array}{c}\text { Sperm } \\
\text { concentration } \\
(\text { Million/ml) }\end{array}$ & $\begin{array}{c}\text { Sperm } \\
\text { motility } \\
(\%)\end{array}$ & $\begin{array}{c}\text { No. } \\
\text { of } \\
\text { oocytes }\end{array}$ & Fertilization & $\begin{array}{c}\text { No. of Embryos } \\
\text { Transferred }\end{array}$ \\
\hline $\mathrm{Z}$ & $-.487-$ & $-.682-$ & $-1.997-$ & $-2.264-$ & $-.372-$ \\
$\mathrm{p}$ value & .626 & .495 & .046 & .024 & .710 \\
\hline
\end{tabular}

Table 3 : Pregnancy rates in cycles with different sperm characteris

\begin{tabular}{|c|c|c|c|c|c|c|}
\hline \multicolumn{4}{|c|}{ Group } & \multicolumn{2}{|c|}{ Semen } & \multirow[t]{2}{*}{ Total } \\
\hline & & & & Fresh & Cryo & \\
\hline \multirow{6}{*}{$\begin{array}{l}\text { Normozoospe } \\
\text { rmia }\end{array}$} & \multirow{4}{*}{$\begin{array}{l}\text { Pregnancy } \\
\text { test }\end{array}$} & \multirow{2}{*}{ no } & Count & 3 & 3 & \multirow{6}{*}{$\begin{array}{c}6 \\
50.0 \% \\
6 \\
50.0 \% \\
12 \\
100.0 \% \\
6\end{array}$} \\
\hline & & & $\%$ within Semen & $50.0 \%$ & $50.0 \%$ & \\
\hline & & & Count & 3 & 3 & \\
\hline & & yes & $\%$ within Semen & $50.0 \%$ & $50.0 \%$ & \\
\hline & \multirow{2}{*}{\multicolumn{2}{|c|}{ Total }} & Count & 6 & 6 & \\
\hline & & & $\%$ within Semen & $100.0 \%$ & $100.0 \%$ & \\
\hline \multirow{6}{*}{$\begin{array}{l}\text { Oligozoosper } \\
\text { mia }\end{array}$} & \multirow{4}{*}{$\begin{array}{l}\text { Pregnancy } \\
\text { test }\end{array}$} & \multirow{2}{*}{ no } & Count & 3 & 3 & \multirow{6}{*}{$\begin{array}{c}54.5 \% \\
5 \\
45.5 \% \\
11 \\
100.0 \% \\
3\end{array}$} \\
\hline & & & $\%$ within Semen & $60.0 \%$ & $50.0 \%$ & \\
\hline & & & Count & 2 & 3 & \\
\hline & & yes & $\%$ within Semen & $40.0 \%$ & $50.0 \%$ & \\
\hline & \multirow{2}{*}{\multicolumn{2}{|c|}{ Total }} & Count & 5 & 6 & \\
\hline & & & $\%$ within Semen & $100.0 \%$ & $100.0 \%$ & \\
\hline \multirow{6}{*}{$\begin{array}{l}\text { Athenozoosp } \\
\text { ermia }\end{array}$} & \multirow{4}{*}{$\begin{array}{l}\text { Pregnancy } \\
\text { test }\end{array}$} & \multirow{2}{*}{ no } & Count & 2 & 1 & \multirow{6}{*}{$\begin{array}{c}42.9 \% \\
4 \\
57.1 \% \\
7 \\
100.0 \% \\
4 \\
40.0 \%\end{array}$} \\
\hline & & & $\%$ within Semen & $50.0 \%$ & $33.3 \%$ & \\
\hline & & & Count & 2 & 2 & \\
\hline & & yes & $\%$ within Semen & $50.0 \%$ & $66.7 \%$ & \\
\hline & \multirow{2}{*}{\multicolumn{2}{|c|}{ Total }} & Count & 4 & 3 & \\
\hline & & & $\%$ within Semen & $100.0 \%$ & $100.0 \%$ & \\
\hline \multirow{6}{*}{$\begin{array}{l}\text { Oligoathenoz } \\
\text { oospermia }\end{array}$} & \multirow{4}{*}{$\begin{array}{l}\text { Pregnancy } \\
\text { test }\end{array}$} & \multirow{2}{*}{ no } & Count & 2 & 2 & \multirow{6}{*}{$\begin{array}{c}60.0 \% \\
10 \\
100 . \%\end{array}$} \\
\hline & & & $\%$ within Semen & $40.0 \%$ & $40.0 \%$ & \\
\hline & & Yec & Count & 3 & 3 & \\
\hline & & yes & $\%$ within Semen & $60.0 \%$ & $60.0 \%$ & \\
\hline & \multirow{2}{*}{\multicolumn{2}{|c|}{ Total }} & Count & 5 & 5 & \\
\hline & & & $\%$ within Semen & $100.0 \%$ & $100.0 \%$ & \\
\hline
\end{tabular}

When we evaluated cycles performed with asthenozoospermic semen, the group with cryopreserved sperm resulted in pregnancy $(60.0 \%$ vs. $50.0 \%)$ rates with fresh and cryopreserved sperm were similar $(\mathrm{P}>.05)$. In cycles performed in patients with oligoasthenozoospermia, the pregnancy 
(40.0\% vs. $40.0 \%)$ rates between fresh and cryopreserved sperm in patients with oligoasthenozoospermia were not different $(\mathrm{P}>.05)$.

\section{DISCUSSION}

Cryopreservation is a widely practiced procedure for storing donor sperm before intrauterine insemination or IVF, for multiple timed artificial inseminations of partner or donor semen to coincide better with irregular female cycles or with special conditions of the female tract, presenting the same or a naturally optimal number of normal-appearing, progressively motile spermatozoa (Anger et al., 2003; Pasqualotto et al., 2003 and Agarwal et al., 2004 ) Sperm also can be cryopreserved before surgical infertility treatment, such as varicocele ligation, or before vasectomy or therapy for malignant diseases (Agarwal et al., 1995; Pasqualotto et al., 2001 and Agarwal et al ., 1991).

The goal in this study was to investigate whether there is any difference in fertilization, implantation, and pregnancy rates in patients undergoing ICSI using either fresh or cryopreserved spermatozoa. The retrospective study showed that although there was a trend for higher fertilization rates in ICSI cycles that use fresh compared with cryopreserved spermatozoa, no differences were detected in the implantation and pregnancy rates. Recently, a study showed that ICSI with fresh or cryopreserved ejaculated sperm yields comparable results in terms of fertilization and embryo quality (Kuczynski et al., 2001).

Other studies have been published evaluating fertilization and pregnancy rates after ICSI, comparing fresh and cryopreserved human spermatozoa (Schlegel et al., 1999; Gil-Salom et al., 1998 and Madgar et al., 1998). However, the different results among the studies published may be since some of the studies were published evaluating testicular or epididymal sperm instead of ejaculated sperm.

It is known that the cryopreservation procedure impairs sperm motility and decreases fertilization rate through detrimental effects on the acrosomal structure and acrosin activity (Colpi et al., 2004; Donnely et al., 2001 and Donnelly et al ., 2001). Sperm cryopreservation affects the mitochondrial function, membrane integrity, and cell viability (Donnely et al ., 2001). Also, it may be detrimental to the chromatin structure, even though a cumulative effect on sperm fertilization capacity has not been definitely established (Donnely et al ., 2001 and Donnelly et al ., 2001). 
The results demonstrated that when the semen sample had low motility, the fertilization rate was higher with fresh sperm than with cryopreserved sperm. However, the embryo implantation, pregnancy, and miscarriage rates were similar. This finding corroborates the idea that the cryopreservation process causes more damage to patients with asthenozoospermia than to patients with normal semen analysis or oligozoospermia. In fact, in this study postulate that the worst normalfertilization rate detected in men with asthenozoospermia compared with normozoospermic or oligozoospermic men may result because the semen with low motility has abnormalities in the sperm even before the cryopreservation and that the damage caused by the cryopreservation thus is much more extensive than is detected from other sperm characteristics.

In conclusion, semen with low motility may be more susceptible to sperm cryopreservation damage, resulting in lower fertilization rates. However, once the oocyte is fertilized, implantation and pregnancy rates are similar to those in patients with oligozoospermia and normozoospermia.

\section{REFERENCES}

Agarwal, A.; Sidhu, R., S.; Shekarriz, M.; Thomas, A., J., Jr. 1995. An optimumabstinence time for cryopreservation of semen in cancer patients. Journal Urol.; 154:86-8.

Agarwal,A.; Newton, R.,A. 1991. The effect of cancer on semen quality aftercryopreservation of sperm. Andrologia; 23:329-32.

Agarwal,A.; Ranganathan ,P.; Kattal ,N.; Pasqualotto, F.,F.; Hallak, J.; KhayalS.; et. al. 2004. Fertility after cancer: a prospective review of assisted reproductive outcome with banked specimens. Fertil Steril , 81:342-8.

Anger, J., T.; Gilbert, B., R.; Goldstein, M. 2003. Cryopreservation of sperm: indication, methods and results. J Urol 2003,170: 1079-84.

Colpi, G., M.; Contabi,G.,F.; Nerva, F.; Sagone, P.; Piediferro, G. 2004. Testicularfunction following chemo-radiotherapy. Eur Journal Obstet Gynecol Reprod Biol., 113 Suppl 1: S2-6.

De Croo, I.; Van der Elst, J.; Everaert, K.; De Sutter, P.; Dhont, M. 1998. Fertilization, pregnancy and embryo implantation rates after ICSI with fresh or frozenthawed testicular spermatozoa. Hum Reprod. , 13:1893-7. 
Donnelly, E.,T.; Steele, E.,K.; McClure, N.; Lewis, S.,E. 2001. Assessment of DNAintegrity and morphology of ejaculated spermatozoa from fertile and infertile men before and after cryopreservation. Hum Reprod. ; 16:1191-1199.

Donnely,E.,T.; McClure, N.; Lewis, S.,E.2001. Cryopreservation of human semenand prepared sperm: effects on motility parameters and DNA integrity. Fertil Steril.; 76:892-900.

Gil-Salom ,M. ; Romero ,J. ; Mínguez, Y.; Molero ,M.,D.; Remohí, J.; Pellicer, A. 1998. Testicular sperm extraction and intracytoplasmic sperm injection: a chance of fertility in nonobstructive azoospermia. Journal Urol. ; 160:2072-3.

Kuczynski, W.; Dhont, M ;Grygoruk, C .;Grochowski,D. ; Wolczynski, S .; Szamatowicz, M. 2001. The outcome of intracytoplasmic injection of fresh and cryopreserved ejaculated spermatozoa-a prospective randomized study. Hum Reprod ; 16:2109-13.

Madgar,I.; Horvitz, A.; Levron, J.; Seidman, D.,S.; Shulman, A.; Raviv, G.,G.; et, al. 1998. Outcome of in vitro fertilization and intracytoplasmic injection of epididymal and testicular sperm extracted from patients with obstructive and nonobstructive azoospermia. Fertil Steril ; 69:1080-4.

Marcus-Braun, N.; Braun, G.; Potashnik, G.; Har-Vardi, I.2004. Effect of cryopreservation on quality and fertilization capacity of human sperm. Eur J Obstet Gynecol Reprod Biol 2004; 116:63-6.

Mortimer, D. 2004. Current and future concepts and practices in human spermcryobanking. Reprod Biomed Online, 2004m 9: 134-151.

Palermo, G., D.; Schlegel, P., N.; Hariprashad ,J.,J.; Ergün , B. ; Mielnik, A. ; Zaninovic ,N., et., al.1999. Fertilization and pregnancy outcome with intracytoplasmic sperm injection for azoospermic men. Hum Reprod. ; 14:741-8.

Palermo, G.; Joris, H; Devroey, P.; Van Steirteghem, A. 1992.Pregnancy afterintracytoplasmic injection of a single spermatozoon into an oocyte. Lancet ; 304:17-8.

Pasqualotto, F., F.; Agarwal, A. 2001. Should we offer semen cryopreservation tomen with testicular cancer? Cleve Clin Journal Med. ; 68:101-2.

Pasqualotto, F., F.; Lucon, A., M, Hallak, J.; Saldanha, L.,B.; Góes, P.,M.; Arap, S. 2003. Induction of spermatogenesis in azoospermic men undergoing varicocele repair. Hum Reprod. ; 18:108-12. 
Pasqualotto, F., F.; Rossi-Ferragut,L.,M . ; Rocha, C. ;Iaconelli ,A., Jr. ; Borges, E., Jr. 2002. Outcome of in vitro fertilization and intracytoplasmic sperm injection of epididymal and testicular sperm obtained from patients with obstructive and nonobstructive azoospermia. Journal Urol. ; 167:1753-1756.

Perraguim-Jayot, S.; Audebert, A. ; Emperaire, J. C.; Parneix, I. 1997. Ongoingpregnancies after intracytoplasmic injection using cryopreserved testicular spermatozoa. Hum Reprod.; 12:2706-9.

Rossi, L., M.; Locambo-Freitas, C., V.; Bonetti, T., C.; Iaconelli, A., Jr.; Rodrigues, D.; Borges, E., Jr.2005. Laboratorial rules for choosing the elective single embryo to be transferred: morphological parameters [abstract]. Fertil Steril ;84(Suppl 1): S288

Sailer, B., L.; Jost, L.,K.; Evenson, D.,P. 1995. Mammalian sperm DNA susceptibility to in situ denaturation associated with the presence of DNA strand breaks as measured by the terminal deoxynucleotidyl transferase assay. Journal Urol.; 16:80-7.

Schlegel, P., N. 1999. Debate: is ICSI a genetic time bomb? No: ICSI is safe and effective. Journal Androl. ; 20:18-22.

Tournaye, H. 1999. Surgical sperm recovery for intracytoplasmic sperm injection: which method is to be preferred? Hum Reprod ; 14:71-81.

Van Steirteghem, A.; Nagy, P.; Joris, H.; Janssenswillen, C.; Staessen, C.; Verheyen ,G., et al. 1998. Results of intracytoplasmic sperm injection with ejaculated, fresh and frozen-thawed epididymal and testicular spermatozoa. Hum Reprod.; 13:134-42.

WHO.1999. World Health Organization. Laboratory manual for the examination of human semen and sperm-cervical mucus interaction. $4^{\text {th }}$ ed. New York: Cambridge University Press. 


\section{دراسة كفاءة الحيوانات المنوية المجمدة والغير مجمدة على نتائج الحقن المجهري}

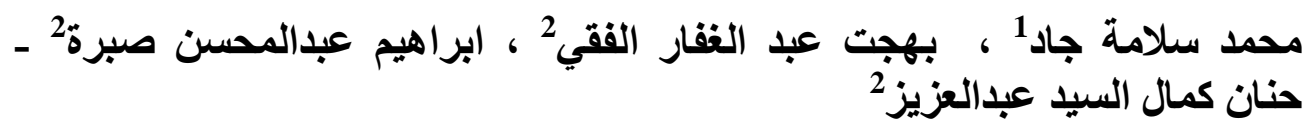

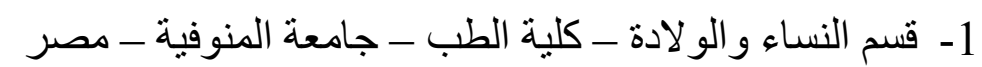

2- قسم البيو تكنولوجيا الحيو انية ، معهد بحوث الهندسة الورة الوراثية و التكنولوجيا الحيوية

$$
\text { ، مامعة مدينة السادات ، مصر. }
$$

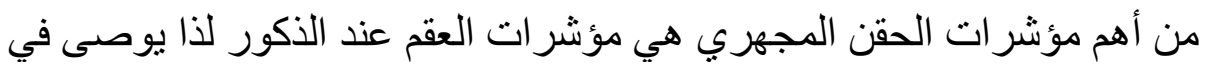

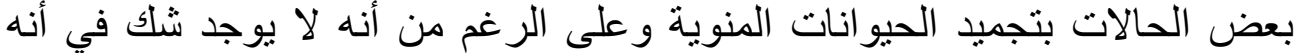

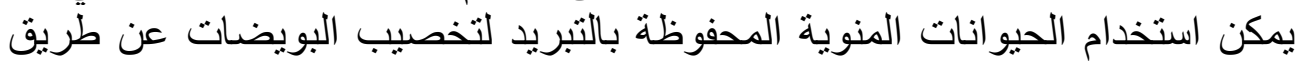

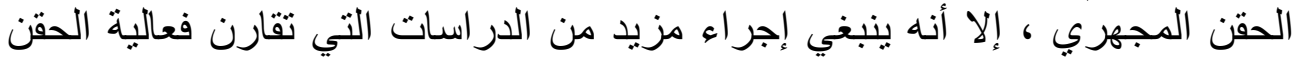

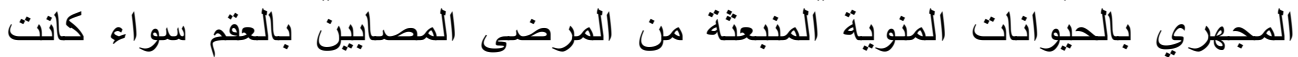

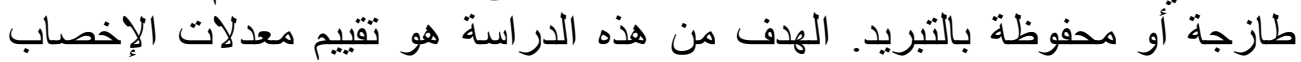

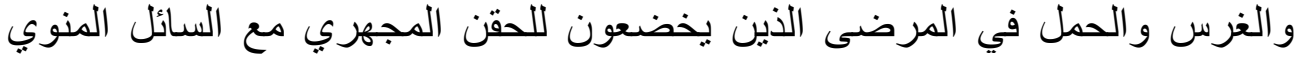
الطاز ج و المحفوظ بالتنبريد.

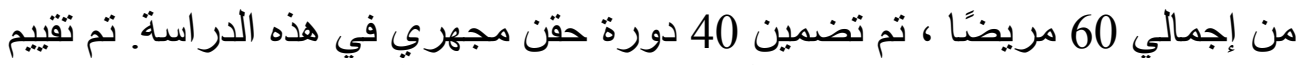

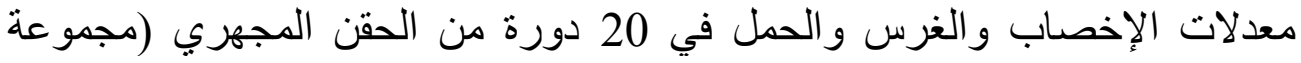

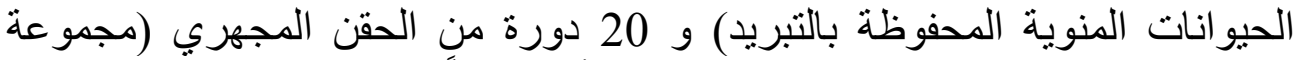

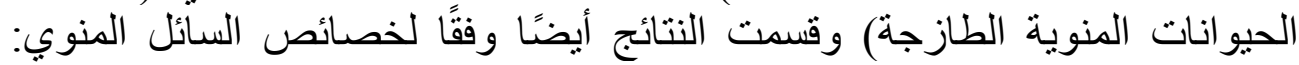
النطاف الطبيعي ، قلة النطاف ، وضعف النطاف ، وقلة النطاف وضعف النقاف الحركة. بشكل عام ، كانت معدلات الإخصاب الطبيعي أعلى باستخدام الحيوانات المنوية التهات

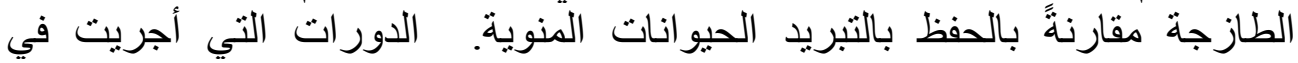

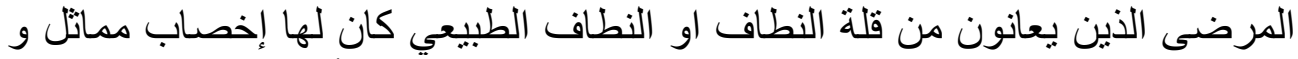

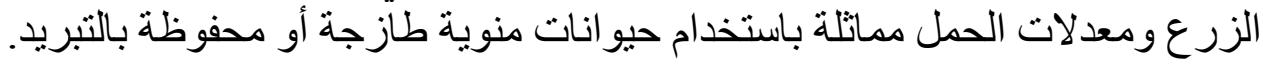

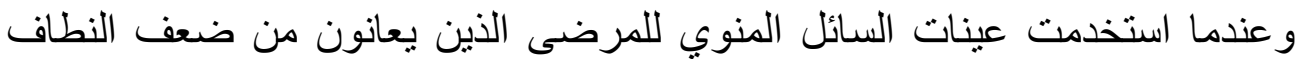

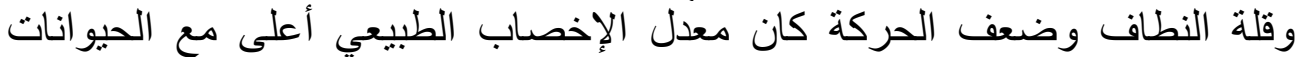

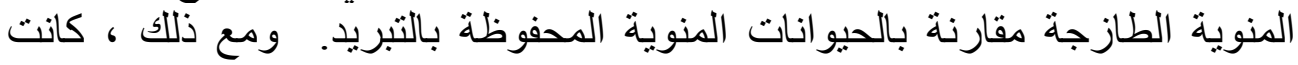


معدلات الزرع والحمل منشابهة في عينات الحيوانات المنوية الطازجة و المحفوظة بالتبريد.

العديد من الدراسات أظهرت أن معدلات الإخصاب والحمل في الحقن المجهري

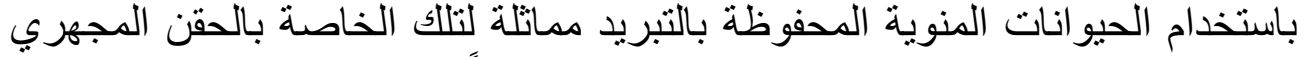
باستخدام الحيو انات المنوية التي تم الحصول المنية عليها حديثًا. التوصية :

على الرغم من أنه لا يوجد شك في أن الحيوانات المنوية المحفوظة بالتبريد يمكن

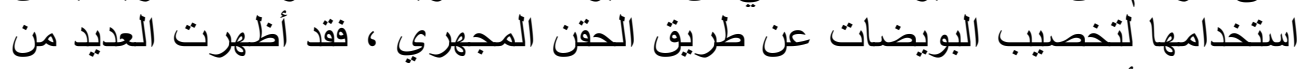

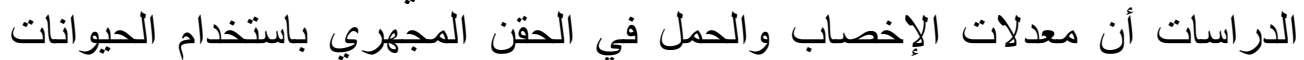

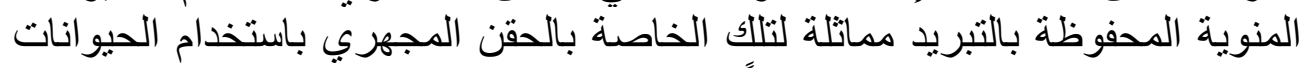

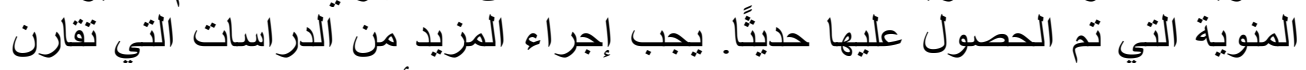

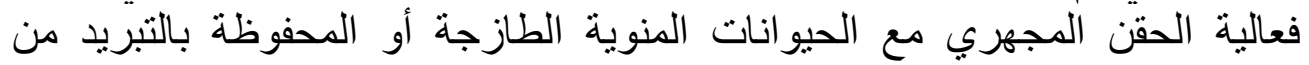
مرضى العقم. 